là 20,4\%; CED nhóm 20- 24 cao nhất (26,6\%) so với tỷ lệ chung 16,2\% ở phụ nữ 20-35 tuổi. Cân nặng, BMI, phân trăm mỡ (\%BF) và khối lượng mỡ (FM), khối lượng cơ ước tính (PMM), khối lượng không mõ (FFM) có sự thay đổi theo lớp tuổi tăng dân. Tỷ lệ SDD thấp còi và CED còn cao ở PNTSĐ, đặc biệt là nhóm tuổi 15-24 tuổi, cân tiếp tục đâuu tư các hoạt động can thiệp dinh dưỡng, tăng cường giáo dục truyền thông nhằm cải thiện tình trạng dinh dưỡng cho đối tượng này, đặc biệt ưu tiên cho PNTSĐ ở nhóm tuổi dưới 25 tuổi tại Sơn La.

\section{TÀI LIỆU THAM KHẢO}

1. Dekker LH, Mora-Plazas M, Marín $C$ et al. Stunting Associated with Poor Socioeconomic and Maternal Nutrition Status and Respiratory Morbidity in Colombian Schoolchildren. Food and Nutrition Bulletin, 2010; 31(2): 242 - 250.

2. Viện Dính dướng. Báo cáo sơ bộ kết quả Tổng điêu tra Dinh dưỡng toàn quốc 2019 - 2020. Hội nghị Công bố kết quả Tổng điêu tra dinh dưỡng, 20211.

3. Đinh Thị Phương Hoa, Lê Thị Hợp, Phạm Thị Thúy Hòa. Thực trạng thiếu máu, tînh trạng dinh dưỡng và nhiếm giun ở phụ nữ 20-35 tuổi tại xã thuộc huyên Lục Nam, Bắc Giang. Tạp chí Dinh dưỡng \& Thực phẩm, 2012; 8(1): 39-46.

4. Ferede $A$, Lemessa $F$, Tafa $M$, Sisay $S$. The prevalence of malnutrition and its associated risk factors among women of reproductive age in Ziway Dugda district, Arsi Zone, Oromia Regional State, Ethiopia. Public Health, 2017; 152: 1-8.

5. Viện Dinh dưỡng, Báo cáo kết quả điều tra dinh dưỡng toàn quốc hàng năm cập nhật đến 2019. Website: http://viendinhduong.vn, 2021.

6. Nguyê̂n Quang Dũng, Nguyễn Lân, Lê Danh Tuyên. Tình trạng dinh dướng, đặc điểm cấu trúc cơ thể của phụ nữ tuổi sinh đẻ người $\mathrm{H}^{\prime}$ Mông tại huyện Bảo Lạc, tỉnh Cao Bằng. Tình hình dinh dưỡing chiến lước can thiêp 2011-2015 và đinh hướng 2016-2020 Nhà xuất bản Y học, 2017; 104-111.

7. Petry N, Al-Mamary S A, Woodruff BA, Alghannami S. National Prevalence of Micronutrient Deficiencies, Anaemia, Genetic Blood Disorders and Over- and Undernutrition in Omani Women of Reproductive Age and Preschool Children. Sultan Qaboos University Med J, 2020; 20(2): e151-164.

8. Sladjana R, Milivej D, Marina DN, Nadja V. Profile and reference values for body fat and skeletal muscle mass percent at females, aged from 18.0 to 69.0, measured by Multichannel Segmental Bioimpedance method: Serbian population study. Int. J. Morphol, 2019; 37(4): 1286-1293.

\title{
MộT Số YẾU TỐ LIÊN QUAN ĐẾN KẾT QUẢ PHẪU THUÂT CẮT DİCH KÍNH ĐÎ̂̉U TRI BONG VÕNG MẠC DO LỖ HOÀNG ĐIỂM
}

\section{TÓM TẮT}

Mục tiêu: Đánh giá môtt số yếu tố liên quan đến kết quả phẫu thuật cắt dịch kính điều trị bong võng mạc do lố hoàng điểm. Đối tượng và phương pháp nghiên cứu: Nghiên cứu mô tả cắt ngang gồm 52 mắt bong võng mạc do lô̂ hoàng điểm đã được phẫu thuật cắt dịch kính bóc màng ngăn trong kết hợp bơm khí nở C3F8 hoặc dầu silicon nội nhãn tại Bệnh viện Mắt Trung ương từ năm 2015 - 2019 với thời gian theo dõi tối thiểu 6 tháng. Kết quả: Tỷ lệ võng mạc áp hoàn toàn sau phấu thuật lần đâu là $80,8 \%$. Tỷ lệ đóng lỗ hoàng điểm hoàn toàn là $61,5 \%$. Thị lực trung bình tăng từ $1,99 \pm 0,31$ logMAR lên $1,35 \pm 0,26$ logMAR ở lần khám sau cùng. Thời gian bị bệnhhh trên 6 tháng, thị lực ban đâuu thấp, trục nhãn cầu trên $\geq 26 \mathrm{~mm}$, sự giä̉n phình hậu cực và kích thước lỗ hoàng điểm lớn là các yếu tố làm giảm tỷ lệ võng mạc áp hoàn toàn và khả năng đóng lố hoàng điểm. Mức độ bong võng mạc rộng làm giảm khả năng đóng lỗ hoàng điểm trong khi chất độn nội nhãn ảnh hưởng

*Bệnh viên Mắt Trung Ương

Chịu trách nhiệm chính: Nguyễn Kiếm Hiệp

Email: nguyenkiemhiep@gmail.com

Ngày nhận bài: 14.6.2021

Ngày phản biên khoa học: 9.8.2021

Ngày duyệt bài: 16.8.2021
Nguyễn Kiếm Hiệp*

đến tỷ lệ áp võng mạc sau mổ. Kích thước lỗ hoàng điểm là yếu tố ảnh hưởng duy nhất đến kết quả thị lực sau phẫu thuật $(p=0,009)$. Kết luận: Phẫu thuật cắt dịch kính điều trị bong vông mạc do lỗ hoàng điểm mang lại kết quả tốt về giải phấu tuy nhiên kết quả thị lực còn thấp. Thời gian bị bệnh, thị lực ban đầu, trục nhãn cầu, sự giãn phình hậu cực, kích thước lỗ hoàng điểm, mức độ bong võng mạc và chất độn nội nhãn là những yếu tổ ảnh hưởng đển kết quả giải phẫu trong khi kích thước lỗ hoàng điểm ảnh hưởng đến kết quả thị lực của phẫu thuật. kính

Tư khóa: bong võng mạc, lỗ hoàng điểm, cắt dịch

\section{SUMMARY}

EVALUATING THE FACTORS RELATED TO OUTCOME OF VITRECTOMY FOR RETINAL DETACHMENT CAUSED BY MACULAR HOLE

Purpose: To evaluate the factors related to outcome of vitrectomy for retinal detachment caused by macular hole. Methods: A cross-sectional descriptive study of 52 macular hole retinal detachment eyes that underwent vitrectomy in combination with inner limiting membrane peeling and intraocular gas (C3F8) or silicone oil at the Viet Nam National Institute of Ophthalmology from 2015 to 2019 with a minimum follow-up of 6 months. Results: The rate of retinal reattachment after the 
primary surgery was $80.8 \%$. The rate of macular hole closure was $61.5 \%$. Mean visual acuity increased from $1.99 \pm 0.31 \log M A R$ to $1.35 \pm 0.26 \log M A R$ at the last examination. Disease duration more than 6 months, poor preoperative visual acuity, axial length more than $26 \mathrm{~mm}$, posterior staphyloma and large macular hole size are factors that reduce the rate of retinal reattachment and macular hole closure after surgery. The extent of retinal detachment reduces the possibility of macular hole closure while intraocular tamponade affects only the rate of postoperative retinal reattachment. The size of the macular hole was the only factor affecting postoperative visual acuity ( $p$ $=0.009$ ). Conclusion: Vitrectomy for macular hole retinal detachment has good anatomical results, but postoperative visual acuity are still low. Disease duration, preoperative visual acuity, axial length, posterior staphyloma, macular hole size, extent of retinal detachment and intraocular tamponade were factors that influenced the anatomic results while the size of the macular hole affects the visual outcome of surgery.

Keywords: retinal detachment, macular hole, vitrectomy

\section{I. ĐẶT VẤN ĐỀ}

Bong võng mạc do lỗ hoàng điểm thường xuất hiện ở mắt cận thị nặng có giãn lồi hậu cực, đòi hỏi can thiệp phẫu thuật sớm bởi bì bong võng mạc do lồ hoàng điểm gây tổn thương võng mạc không hồi phục [1]. Ở mặt cận thị nặng, bong võng mạc do lố hoàng điểm được cho là do những co kéo tiếp tuyến tại vùng hoàng điểm, giãn lồi hậu cực, hoặc do teo lớp biểu mô sắc tố $[1,2]$.

Phẫu thuật cắt dịch kính, bóc màng ngăn trong kết hợp khí nở nội nhãn hoặc dầu silicon nội nhãn là phương pháp điều trị chính với tỷ lệ áp võng mạc khá cao, từ $50-90 \%[3 ; 4 ; 5]$. Tuy nhiên, bong võng mạc do lỗ hoàng điểm vẫn là một trong những loại bong võng mạc khó điều trị. Tỷ lệ bong võng mạc tái phát còn khá cao, việc đóng lỗ hoàng điểm và phục hồi thị lực vẫn còn là vấn đề khó khăn. Việc hiểu biết về các yếu tố liên quan sẽ giúp phẫu thuật viên tiên lượng tốt hơn và cải thiện kết quả phẫu thuật. Tuy nhiên ở Việt Nam hiện nay chưa có nghiên cứu nào về vấn đề này.

Vì vậy, chúng tôi tiến hành nghiên cứu nhằm đánh giá một số yếu tố liên quan đến kết quả phẫu thuật cắt dịch kính điêu trị bong võng mạc do lỗ hoàng điểm.

\section{II. ĐỐI TƯỢNG VÀ PHƯƠNG PHÁP NGHIÊN CỨU}

1. Đối tượng nghiên cứu. Nghiên cứu được tiến hành tại khoa Dịch kính - Võng mạc, Bệnh viện Mắt Trung Ương từ tháng 1/2015 đến tháng $1 / 2019$.

a) Tiêu chuẩn lựa chọn: - Bệnh nhân bị bong võng mạc do lỗ hoàng điểm.

- Lỗ hoàng điểm độ 3, 4.

- Thị lực từ nhận biết ánh sáng (ST(+)) trở lên.

- Bềnh nhân trên 18 tuổi.

- Bệnh nhân đồng ý tham gia nghiên cứu.

b) Tiêu chuẩn loại trừ:

- Bong võng mạc lố hoàng điểm nhưng có vết rách võng mạc.

- Có bệnh lý khác của nhãn cầu ảnh hưởng đến kết quả phẫu thuật như mộng độ 3 hoặc 4 , sẹo giác mạc dày.

- Bênh nhân được phẫu thuật thủy tinh thể có đặt kính nội nhãn nhưng khi phẫu thuật không đặt được kính.

- Bệnh nhân già yếu hoặc có bệnh toàn thân nặng.

- Bệnh nhân không hợp tác.

2. Phương pháp nghiên cứu. Nghiên cứu mô tả cắt ngang

Cõ mẫu: 52 bệnh nhân. Áp dụng phương pháp chọn mấu thuận tiện.

* Cách thức tiến hành:

- Khám BN trước mổ bằng sinh hiển vi, làm xét nghiệm cần thiết: siêu âm, chụp OCT bán phần sau,..

- Thu thập các thông tin vào bệnh án nghiên cứu:

+ Hành chính: tên, tuổi, giới, địa chỉ.

+ Đặc điểm lâm sàng: thời gian bị bệnh, thị lực, nhãn áp, trục nhãn cầu, giãn phình hậu cực, mức độ bong võng mạc, kích thước lỗ hoàng điểm,...

- Tiến hành phẫu thuật: gây tê cạnh nhãn cầu lydocain $2 \%$, cắt dịch kính qua pars plana với troca 23G, đầu cắt dịch kính, camera nội nhãn, thuốc nhuộm màng ngăn trong, pince bóc màng, bơm khí nở C3F8 hoặc dâu silicon nội nhãn, có hoặc không kèm theo lây thể thủy tinh đặt thể thủy tinh nhân tạo, nằm sấp 2 tuần sau phẫu thuật. Tháo dâu silicon sau 3 tháng.

- Theo dõi sau mổ ở các thời điểm sau phẫu thuật 1 ngày, 1 tuần, 1 tháng, 3 tháng, 6 tháng: khám mắt bằng sinh hiển vi, phát hiện biến chứng, đo thị lực, siêu âm, chụp OCT đánh giá võng mạc và iố hoàng điểm ở mổi thời điểm theo dõi, ghi nhận các thông tin vào bệnh án nghiên cứu.

- Xử lý và phân tích số liệu.

* Các biến số nghiên cứu:

- Kết quả giải phẫu:tỷ lệ võng mạc áp hoàn toàn, tỷ lệ đóng lỗ hoàng điểm sau phẫu thuật.

- Kết quả chức năng: thị lực sau mổ ở lần khám cuối cùng.

- Khảo sát các yếu tố liên quan đến kết quả phẫu thuật bao gồm: tuổi, giới, thời gian bi bệnh, thị lực đầu vào, trục nhãn cầu, phình giãn hậu cực, mức độ bong võng mạc, kích thước lỗ 
hoàng điểm, chất độn nỗi nhãn.

3. Xử lý số liệu. Sử dụng phần mềm thống kê SPSS 16.0 với các biến dùng thuật toán so sánh 2 nhóm Mann-Whitney $U$ tests hoăc Fisher's exact tests. Sự khác biệt có ý nghĩa thống kê khi $p<0,05$.

\section{KẾT QUẢ NGHIÊN CỨU}

Nghiên cứu gồm 52 mắt ( 52 bệnh nhân) bong võng mạc lỗ hoàng điểm được phẫu thuật cắt dịch kính, bóc màng ngăn trong, bơm khí nở hoặc dầu silicon nội nhãn tại Bênh viên Mắt Trung ương từ năm 2015 - 2019. Tỷ lệ nữ chiếm $75 \%$, tuổi trung bình là 62 ( từ $48-79$ tuổi). Thị lực trung bình trước phẫu thuật là 1,98 $\pm 0,31$ logMAR (BBT 0,1m đến 20/400)

\section{Bảng 1. Kêt quả phẫu thuật}

\begin{tabular}{|c|c|}
\hline Tỷ lệ võng mạc áp & $80,8 \%$ \\
\hline Tỷ lệ đóng lố hoàng điểm & $61,5 \%$ \\
\hline Thị lực & $1,35 \pm 0,26$ logMAR \\
(ĐNT 0,5m - 20/100) \\
\hline
\end{tabular}

Tỷ lê võng mac áp sau phẫu thuật lần đầu là 80,8\%. Có 10 bệnh nhân (19,2\%) bị bong võng mạc tái phát cần phẫu thuật lần 2 và bơm dầu silicon nội nhãn. Các trường hợp này võng mạc đều áp sau khi tháo dầu. Tỷ lệ đóng lỗ hoàng điểm hoàn toàn là $61,5 \%$, còn lại $38,5 \%$ đều có sự giảm kích thước lố so với trước khi phẫu thuật. Thị lực ở lần khám sau cùng có sự cải thiện đáng kể từ $1,99 \pm 0,31 \log M A R$ (BBT 0,1m - 20/400) lên $1,35 \pm 0,26$ logMAR (DNT 0,5m 20/100) với $\mathrm{p}<0,0001$.

\section{Bảng 2. Các yếu tố ảnh hưởng đến kêt quả giải phẫu}

\begin{tabular}{|c|c|c|c|c|c|c|c|}
\hline \multicolumn{2}{|c|}{ Các yếu tố ảnh hưởng } & $\begin{array}{l}\text { Áp hoàn } \\
\text { toàn }\end{array}$ & $\begin{array}{l}\text { BVM tái } \\
\text { phát }\end{array}$ & $\mathbf{P}$ & $\begin{array}{l}\text { Đóng } \\
\text { LHĐ }\end{array}$ & \begin{tabular}{|c|} 
Không \\
đóng LH円
\end{tabular} & $\mathbf{p}$ \\
\hline \multirow{2}{*}{$\begin{array}{l}\text { Thời gian } \\
\text { bị bệnh }\end{array}$} & $\leq 6$ tháng & 38 & 9 & \multirow{2}{*}{0,04} & 31 & 16 & \multirow{2}{*}{0,045} \\
\hline & $>6$ tháng & 4 & 1 & & 1 & 4 & \\
\hline \multirow{3}{*}{$\begin{array}{l}\text { Thị lực ban } \\
\text { đâuu }\end{array}$} & $<20 / 100-\geq 20 / 400$ & 3 & 1 & \multirow{3}{*}{0,047} & 3 & 1 & \multirow{3}{*}{0,0084} \\
\hline & $<20 / 400-\geq$ DNT1m & 9 & 1 & & 7 & 3 & \\
\hline & $<$ DNT $1 \mathrm{~m}$ & 30 & 8 & & 22 & 16 & \\
\hline \multirow{3}{*}{$\begin{array}{l}\text { Mức độ } \\
\text { bong võng } \\
\text { mạc }\end{array}$} & Khu trú hậu cực & 33 & 6 & \multirow{3}{*}{0,351} & 27 & 12 & \multirow{3}{*}{0,04} \\
\hline & $\begin{array}{c}\text { Hậu cực } \\
\text { và } 1 \text { góc phần tư }\end{array}$ & 5 & 3 & & 2 & 6 & \\
\hline & $\begin{array}{c}\text { Hậu cực } \\
\text { và } 2 \text { góc phâan tư }\end{array}$ & 4 & 1 & & 3 & 2 & \\
\hline \multirow{3}{*}{$\begin{array}{l}\text { Trục nhãn } \\
\text { câuu }\end{array}$} & $<24 \mathrm{~mm}$ & 2 & 0 & \multirow{3}{*}{0,038} & 2 & 0 & \multirow{3}{*}{0,032} \\
\hline & $\geq 24-<26 \mathrm{~mm}$ & 5 & 0 & & 4 & 1 & \\
\hline & $\geq 26 \mathrm{~mm}$ & 35 & 10 & & 26 & 19 & \\
\hline \multirow{3}{*}{$\begin{array}{l}\text { Kích thước } \\
\text { LHĐ }\end{array}$} & $<400 \mu \mathrm{m}$ & 1 & 0 & \multirow{3}{*}{0,038} & 1 & 0 & \multirow{3}{*}{0,013} \\
\hline & $\geq 400-<600 \mu m$ & 17 & 0 & & 15 & 2 & \\
\hline & $\geq 600 \mu \mathrm{m}$ & 24 & 10 & & 16 & 18 & \\
\hline \multirow{2}{*}{$\begin{array}{l}\text { Giãn phình } \\
\text { hậu cực }\end{array}$} & Có & 35 & 10 & \multirow{2}{*}{0,016} & 26 & 19 & \multirow{2}{*}{0,015} \\
\hline & Không & 7 & 0 & & 6 & 1 & \\
\hline \multirow{2}{*}{ Chất độn } & Khí nở C3F8 & 6 & 7 & \multirow{2}{*}{0,001} & 6 & 7 & \multirow{2}{*}{0,188} \\
\hline & Dâu silicon & 36 & 3 & & 26 & 13 & \\
\hline
\end{tabular}

Thời gian bị bệnh > 6 tháng, thị lực ban đầu thấp, trục nhã̉n cầu dài, kích thước lỗ hoàng điểm lớn và giãn phình hậu cực là những yếu tố ảnh hưởng đến tỷ lệ áp võng mạc và đóng lỗ hoàng điểm $(p<0,05)$. Trong khi đó mức độ bong võng mạc ảnh hưởng đến khả năng đóng lỗ hoàng điểm $(p=0,04)$ nhưng không ảnh hưởng đến tỷ lệ áp võng mạc $(p=0,351)$. Ngược lại, chất độn nội nhãn ảnh hưởng đến tỷ lệ áp võ̀ng mạc $(p=0,01)$ nhưng không ảnh hưởng đến khả năng đóng lỗ hoàng điểm ( $p=$ 0,188 ). Các yếu tố khác như tuổi, giới, tình trạng dịch kính sau, cách bóc màng giới hạn trong và thời gian nằm sấp đều không ảnh hưởng đến kết quả giải phẫu của phẫu thuật $(p>0,05)$.

Bảng 3. Ánh hướng của kích thước lố hoàng điểm đến thị lực sau mố

\begin{tabular}{|c|c|c|c|}
\hline $\begin{array}{l}\text { Kết quả } \\
\text { thị lực }\end{array}$ & $\begin{array}{l}\text { Kích thước } \\
\text { LHĐ }(\mu \mathrm{m})\end{array}$ & $n(\%)$ & $\mathbf{P}$ \\
\hline$\geq 20 / 100$ & 468 & $1(1,9 \%)$ & \multirow{4}{*}{0,009} \\
\hline $\begin{array}{l}<20 / 100- \\
\geq 20 / 400\end{array}$ & 635,4 & $\begin{array}{c}27 \\
(51,9 \%) \\
\end{array}$ & \\
\hline $\begin{array}{l}<20 / 400- \\
\geq \text { DNT } 1 \mathrm{~m}\end{array}$ & 761,6 & $\begin{array}{c}23 \\
(44,3 \%)\end{array}$ & \\
\hline$<$ DNT 1m & 964 & $1(1,9 \%)$ & \\
\hline
\end{tabular}

1 mắt có thị lực tốt nhất sau phẫu thuật $(\geq$ 20/100) có kích thước LHĐ nhỏ nhất là $468 \mu \mathrm{m}$ và 1 mắt có thị lực kém nhất (< ĐNT $1 \mathrm{~m})$ có 
kích thước LHĐ lớn nhất là $964 \mu \mathrm{m}$. Nhóm có thi lực từ $\geq 20 / 400-<20 / 100(51,9 \%)$ và từ ĐNT $1 \mathrm{~m}-<20 / 400(44,3 \%)$ có kích thước LHĐ trung bình lân lượt là 635,4 và $761,6 \mu \mathrm{m}$. Như vậy, kích thước î̃̂ hoàng điểm có liên quan tới kết quả thị lực sau phẫu thuật. Lỗ hoàng điểm lớn thì kết quả thị lực sau phấu thuật thấp hơn. Khác biệt có ý nghĩa thống kê với $p=0,009$. Khảo sát các yếu tố khác không thấy sự ảnh hưởng có ý nghĩa thống kê đến kết quả thị lực sau phẫu thuật $(0<0,05)$.

\section{BÀN LUÂN}

Nghiên cứu của chúng tôi gồm 52 mắt bong võng mạc do lỗ hoàng điểm được phẫu thuật cắt dịch kính, bóc màng ngăn trong, bơm khí nở hoặc dâuu silicon nội nhãn tại Bệnh viện Mắt Trung ương. Kết quả cho thấy tỷ lệ võng mạc áp sau lần mổ đầu là $80,8 \%$. Chỉ có 10 trường hợp $(19,2 \%)$ bong tái phát được phẫu thuật lần 2 và bơm dầu nội nhãn. ở các bệnh nhân này võng mạc đều áp sau khi tháo dầu. Có $61,5 \%$ đóng lỗ hoàng điểm sau mổ. Các kết quả này khá tương đồng với nghiên cứu của Nishimura (92\%; 55\%), Kakinoki $(85 \% ; 53,5 \%)$ và $\operatorname{Lim}(86 \% ; 52 \%)$ $[3 ; 4 ; 5]$. Thị lực trung bình tăng từ 1,99 $\pm 0,31$ logMAR lên 1,35 $\pm 0,26$ logMAR ở lần khám sau cùng.

Nhóm bệnh nhân có thời gian mắc bệnh ngắn hơn 6 tháng có tỷ lệ áp lại võng mạc là 38/47 mắt $(80,9 \%)$ và tỷ lệ đóng lỗ hoàng điểm là $31 / 47$ mắt (66\%), cao hơn đáng kể so với nhóm có thời gian bị bệnh dài hơn, với tỷ lệ tương ứng là $80 \%$ và $20 \%$. Như vậy, thời gian xuất hiện bệnh ngắn hơn thì tỷ lệ võng mạc áp và đóng lỗ hoàng điểm cao hơn ( $p$ lần lượt là 0,04 và $0,045)$, tương tự kết quả của Lam và cộng sư (2006) [6]. Bệnh càng kéo dài thì kích thước lố hoàng điểm càng lớn kèm theo thời gian bong võng mạc càng lâu thì càng gây tổn hại lớp biểu mô sắc tố vốn đã teo ở mắt cận thị nên hạn chế khả năng đóng lỗ và áp lại võng mạc. Vì vậy, phát hiện bệnh sớm và điêu trị kịp thời rất quan trọng để đảm bảo thành công của phẫu thuật.

Thị lực ban đâu có liên quan tới kêt quả giải phẫu của phẫu thuật. Thi lực càng kém thì khả năng áp võng mạc và đóng lỗ hoàng điểm sau mổ càng thấp ( $p$ lần lượt là 0,047 và 0,0084 ). Thị lực ban đâu là hậu quả của bệnh trên chức năng của mắt, do ảnh hưởng của những tổn hại về giải phẫu như dịch kính, võng mạc, cùng với các bệnh lý tồn tại sẵn có như đục thể thủy tinh, giãn phình củng mạc, mắt cận thị cao có teo hắc võng mạc. Thị lực ban đầu kém hơn biểu hiện các tổn hại nhãn cầu nặng hơn, nên khả năng phục hồi sau phẫu thuật han chế hơn. Nhiều nghiên cứu cũng chỉ ra mối liên quan này và coi thị lực trước phầu thuật là yếu tố tiên lượng cho kểt quả giải phẫu.

Nakanishi khảo sát các yếu tố tiên lượng áp võng mạc sau phẫu thuật cắt dịch kính và bơm khí nở nội nhãn ở bệnh nhân bong võng mạc do Iỗ hoàng điểm, nhân thấy trục nhãn cầu là một yếu tố tiên lượng cho việc dính lại của võng mạc [7]. Ở mắt có trục nhãn câuu dài hơn, củng mạc kéo dài ra phía sau hơn, dẫn đến lực kéo theo hướng ngược lại lên võng mạc manh hơn. Măc dù phẫu thuât loai bỏ màng dịch kính trước hoàng điểm làm giảm lực kéo theo phương tiếp tuyến lên võng mạc, nhưng nó có thể không đủ so với lực kéo ngược manh hơn trong mắt có trục nhãn cầu dài hơn. Trong nghiên cứu của chúng tôi bong võng mạc tái phát chỉ gặp ở những mắt có trục nhãn câu dài hơn $26 \mathrm{~mm}$ (10/45 mắt; $22,2 \%)$ mà không thấy ở những mắt có trục nhãn cầu ngắn hơn và khác biêt này có ý nghĩa thống kê $(p=0,038)$. Kết quả này cũng tương tự như trong nghiên cứu của Lam và cộng sự [6]. Tác giả lý giải rằng ở mắt có trục nhãn cầu dài, võng mạc hậu cực có thể không đủ so với chiếu dài phía sau của củng mạc, dẫn đến không cân xứng giữa các mô này. Khi phần võng mạc bị bong và thiếu tương đối này bị ép vào thành sau bởi chất đôn, võng mac, đặc biệt là vùng quanh lỗ hoàng điểm, có thể bị kéo căng ly tâm, ngăn chặn khả năng áp võng mạc và đóng lố hoàng điểm. Một số tác giả nhận thây trục nhãn câu không liên quan tới kết quả giải phẫu của lỗ hoàng điểm [6] nhưng trong nghiên cứu của chúng tôi, nhóm trục nhãn cầu dài có tỷ lệ đóng lỗ hoàng điểm sau phẫu thuật thấp hơn ( $p=0,032)$. Nghiên cứu của Ghoraba và cộng sự (2014) đã chỉ ra yếu tố nguy cơ của bong võng mạc tái phát sau phẫu thuật điều trị bong võng mạc do lỗ hoàng điểm là cận thi cao và giãn phình hậu cực [8]. Chúng tôi nhận thấy rằng tất cả mắt bong võng mạc tái phát đều là mắt cận cao (trên 12 đi-ốp) và giãn phình hậu cực, các mắt không giãn phình hậu cực võng mạc đều áp. Tỷ lệ đóng lố hoàng điểm cũng cao hơn ở những mắt không có giãn phình hậu cực $(p=0,015)$. Như vậy, chiều dài trục nhãn cầu và giãn phình hậu cực là một yếu tố quan trọng trong tiên lượng phẫu thuật cắt dich kính điêu trị bong võng mạc do lỗ hoàng điểm.

Trong nghiên cứu này, các mắt có lỗ hoàng điểm nhỏ hơn thì tỷ lệ bong võng mạc tái phát thấp hơn và khả năng đóng lỗ hoàng điểm cao hơn ( $p$ lần lượt là 0,038 và 0,013 ). Lỗ có kích 
thước nhỏ hơn $600 \mu m$ không có bong võng mạc tái phát và lỗ dưới $400 \mu m$ đều đóng hoàn toàn sau phẫu thuật. Xie và Lei (2013) cũng đưa ra kết luận tương tự khi cho rằng lỗ hoàng điểm lớn là yếu tố nguy cơ của bong võng mạc tái phát [9].

Nghiên cứu của chúng tôi không thấy sự khác biệt có ý nghĩa thống kê giữa mức độ bong võng mạc và tỷ lệ áp võng mạc sau phẫu thuật ( $p=$ 0,351 ). Tỷ lể này ở nhóm bong võng mạc khu trú hậu cực là 84,6\%, nhóm bong hậu cực và một góc phần tư và hai góc phần tư lần lượt là $62,5 \%$ và $80 \%$. Tuy nhiên, diện tích bong võng mạc có ảnh hưởng tới khả năng đóng lỗ hoàng điểm. Bong võng mạc càng rộng thì khả năng đóng lỗ hoàng điểm càng thấp $(p=0,04)$. Nhóm bong võng mạc rộng gồm hậu cực và một đến hai góc phần tư chỉ có tỷ lệ đóng LHĐ là $25 \%$ và $60 \%$ tương ứng, trong khi tỷ lệ này ở nhóm chỉ bong hậu cực là $69,2 \%$. Tuy nhiên nghiên cứu của Nakanishi và cộng sự không nhận thấy mối liên quan này [7].

Trong số 13 bệnh nhân được sử dụng khí nở C3F8 có 7 bệnh nhân có bong võng mạc tái phát cần can thiệp lại bơm dâu silicon nội nhãn $(53,8 \%)$. Tỷ lệ áp của võng mạc sau phẩu thuật cắt dịch kính bơm khí nở nội nhãn được báo cáo trong các nghiên cứu trước đây là $50-91 \%[4 ; 7]$. Nghiên cứu của chúng tôi tỉ lệ thành công áp lại võng mạc sau phẫu thuật lần đâu thấp hơn với tỉ lệ thành công $46,2 \%$. Tỷ lệ áp lại của võng mạc sau phẫu thuật cắt dịch kính với khí nở nội nhã̉n trong nhiều nghiên cứu được báo cáo là không khả quan, bệnh nhân sau đó cần phẫu thuật lại nhiều lần. Tác giả nhấn mạnh rằng thị lực sau phẫu thuật có liên quan chặt chẽ với khả năng áp lại của võng mạc ngay sau phẫu thuật vì càng thực hiện nhiều phẫu thuật bổ sung sau đó thì tiên lượing thị lực càng kém. Trong 39 bệnh nhân sử dụng dầu silicon nội nhãn, tỷ lệ áp võng mạc sau phẩu thuật là $92,3 \%$, tương đương với kết quả đã được Nishimura và cộng sự (92\%) [3]. Chúng tôi nhận thấy nhóm bệnh nhân có sử dụng dầu silicon nội nhãn có tỷ lệ bong võng mạc tái phát thấp hợn so với nhóm bệnh nhân sử dụng khí nở C3F8 $(p=0,001)$. Trong khi nghiên cứu của Kakinoki cho kết quả ngược lại với tỷ lệ áp ngay sau phẫu thuật của võng mạc với các mắt dùng khí nội nhãn là $91 \%$ so với dùng dầu chỉ là $73 \%$ [4]. Các tác giả khuyến cáo cân nhắc sử dụng dâu trên các mắt có tiên lượng kém như cận thị cao hoặc giãn phình hậu cực nhưng vẫn cần thêm các nghiên cứu so sánh.

Trong nghiên cứu của chúng tôi, kích thước lỗ hoàng điểm là yếu tố duy nhất ảnh hưởng tới kết quả thị lực sau phẫu thuât. Lỗ hoàng điểm lớn thì kết quả thị lực sau phẫu thuật thấp hơn $(p=$ 0,009 ). Liên quan của kích thước lỗ hoàng điểm trước phẫu thuật và kết quả thị lực sau phẫu thuật có thể do khả năng phục hồi về mặt giải phẫu ở các mắt có lỗ hoàng điểm lớn hợn thì kém hơn so với các mắt có lỗ hoàng điểm nhỏ. Chúng tôi cũng nhận thấy tỷ lệ đóng lỗ hoàng điểm và áp lại võng mạc ở các mắt có lỗ hoàng điểm nhỏ cao hơn có ý nghĩa thống kê so với các mắt có lỗ kích thước lớn ( $p$ lần lượt là 0,013 và 0,038). Nghiên cứu của Lam và cộng sự cũng nhận thấy rằng những mắt có thành công về mặt giải phẫu tốt hơn thì sự cải thiện chức năng cũng tốt hơn, cụ thể là thị lực chỉnh kính tối đa sau mổ ở nhóm bệnh nhân đóng lỗ hoàng điểm là 1,32 logMAR, cao hơn có ý nghĩa thống kê so với nhóm không đóng lỗ là 0,45 logMAR [6]. Ikuno cũng có kết luận tương tự và nhẩn mạnh đóng lỗ hoàng điểm là yếu tố quan trọng để cải thiện thị lực ở các mắt bong võng mạc do lỗ hoàng điểm [10]. Như vậy, việc đánh giá kích thước lỗ hoàng điểm trước phẫu thuật là một thao tác cần thiết để tiên lượng cho thành công của phẫu thuật cả về giải phẩu và chức năng.

Nghiên cứu của chúng tôi còn một số hạn chế. Thứ nhất, số lượng bệnh nhân còn ít cần tiếp tục nghiên cứu để có lượng bệnh nhân lớn hơn. Thứ hai, 6 tháng theo dõi sau mổ vẫn còn quá ngắn bởi bong võng mạc tái phát có thể xảy ra sau đó. Thứ ba, chúng tôi chỉ đánh thị lực trung tâm, những chức năng thị lực khác như thị trường chưa được đánh giá.

\section{KẾT LUẬN}

Phẫu thuật cắt dịch kính điêu trị bong võng mạc do lỗ hoàng điểm mang lại kết quả tốt về giải phẫu tuy nhiên kết quả thị lực còn thấp. Thời gian bị bệnh, thị lực ban đâu, trưc nhãn cầu, sự giãn phình hậu cực, kích thước lố hoàng điểm, mức độ bong võng mạc và chất độn nội nhãn là những yếu tố ảnh hưởng đến kết quả giải phẫu trong khi kích thước lỗ hoàng điểm ảnh hưởng đến kết quả thị lực của phẫu thuật.

\section{TÀl LIÊU THAM KHẢO}

1. Morita $\mathbf{H}$, Ideta $\mathbf{H}$, Ito $\mathbf{K}$, et al. Causative factors of retinal detachment in macular holes. Retina 1991;11:281-284

2. Gao $X$, Guo J, Meng $X$, et al. A meta-analysis of vitrectomy with or without internal limiting membrane peeling for macular hole retinal detachment in the highly myopic eyes. BMC Ophthalmol 2016;16:87

3. Nishimura A, Kimura M, Saito Y, Sugiyama K. Efficacy of Primary Silicone Oil Tamponade for the Treatment of Retinal Detachment Caused by 
Macular Hole in High Myopia. American Journal of Ophthalmology. 2011;151(1):148-155.

4. Kakinoki M, Araki T, Iwasaki $M$, et al. Surgical Outcomes of Vitrectomy for Macular Hole Retinal Detachment in Highly Myopic Eyes. Ophthalmology Retina. 2019;3(10):874-878.

5. Lim LS, Tsai A, Wong $D$, et al. Prognostic Factor Analysis of Vitrectomy for Retinal Detachment Associated with Myopic Macular Holes. Ophthalmology. 2014;121(1):305-310.

6. Lam RF, Lai WW, Cheung BTO, et al. Pars Plana Vitrectomy and Perfluoropropane (C3F8) Tamponade for Retinal Detachment Due to Myopic Macular Hole: A Prognostic Factor Analysis. American Journal of Ophthalmology. 2006;142(6):938-944.e2.

7. Nakanishi H, Kuriyama $S$, Saito $I$, et al. Prognostic Factor Analysis in Pars Plana Vitrectomy for Retinal Detachment Attributable to Macular
Hole in High Myopia: A Multicenter Study. American Journal of Ophthalmology. 2008;146(2):198-204.e1.

8. Ghoraba HH, Elgouhary SM, Mansour HO. Silicone Oil Reinjection without Macular Buckling for Treatment of Recurrent Myopic Macular Hole Retinal Detachment after Silicone Oil Removal. Journal of Ophthalmology. 2014;2014:1-5.

9. Xie A, Lei J. Pars Plana Vitrectomy and Silicone Oil Tamponade as a Primary Treatment for Retinal Detachment Caused by Macular Holes in Highly Myopic Eyes: A Risk-Factor Analysis. Current Eye Research. 2013;38(1):108-113.

10. Ikuno $Y$, Sayanagi $K$, Oshima $T$, et al. Optical coherence tomographic findings of macular holes and retinal detachment after vitrectomy in highly myopic eyes. American Journal of Ophthalmology. 2003;136(3):477-481.

\title{
SỰ HÀI LÒNG NGƯờI BÊNH VỀ GIAO TIẾP CỦA NGƯỜI ĐIỂU DƯỠNG
}

\author{
Nguyễn Thị Hoàng Yến*, Võ Hồng Khôi*, Nguyễn Ngọc Hòa**
}

\section{TÓM TẮT}

Đặt vấn đề: Nâng cao thái độ giao tiếp của điều dưỡng viên với bệnh nhân trong công tác chăm sóc điêuu trị phải luôn được chú trọng nhằm hướng tới sự hài lòng của người bệnh bởi những điều đó ảnh hưởng rất lớn tới chất lượng và hiêu quả chăm sóc. Vì vậy, nghiên cứu khảo sát mối liển quan giữa sự hài long của ngươoi bênh với giao tiếp của điều dướng viên là thực sự cần thiết. Mục tiêu: Đánh giá sự hài lòng của người bệnh về giao tiếp của người điều dưỡng tại Trung tâm Thần Kinh - Bệnh Viện Bạch Mai từ tháng 02/2021đến tháng 06/2021. Phướng pháp nghiên cứu: Nghiên cứu theo phương pháp mô tả cắt ngang trên 238 đối tượng được lựa chon ngấu nhiên. Dữ liệu được thu thập bởi bộ câu hỏi về sự hài lòng của bệnh nhẩn và sự giao tiếp của điêu dướng đã được tác giả Đinh Ngọc Thành xây dựng và tiển hành trên 197 bênh nhần nội trú tại Bênhi Viên A Thái Nguyên [1] với bố câu hỏi tự điền 36 câu của 2 bô câu hỏi trên 5 điểm của thang đo "Likert scale." Với bộ câu hỏi "Sự hài lòng của bệnh nhân với giao tiếp của điều dưỡng" điểm đánh giá từ 1 là rất không hài lòng đến 5 là rất hài lòng. Điểm cao chỉ ra mức đô hài lòng cao. Còn với bộ câu hỏi "Sự giao tiếp của điều dưỡng" điểm đánh giá từ 1 là khống bao giờ đến 5 là rất thường xuyên. Điểm cao chỉ ra mức độ cao về giao tiếp. Kết quả: Các đối tượng tham gia nghiên cứu có tuổi trung bình là $52,96 \pm 16,4$, nữ chiếm ưu thế $(51,3 \%)$, tỷ lệ kết

\section{*Bênh Viện Bach Mai}

**Bênh viện Hữu nghị Đa khoa Nghệ An

Chịu trách nhiệm chính: Nguyễn Ngọc Hòa

Email: tranxuanhoa0510@gmail.com

Ngày nhận bài: 15.6.2021

Ngày phản biên khoa hoc: 10.8.2021

Ngày duyệt bài: 17.8.2021 hôn đạt $(88 \%)$, tập trung nhiêu ở trình độ cấp II và cấp III $(45,8$ và $34,9 \%)$, đa số có BHYTं $(89,9 \%)$, ngày nằm viên trung bình là $5-10$ (48,3\%). Điểm trung bình sự hài lòng của người bệnh là $4,33 \pm 0,516$, điểm trung bình về sư giao tiếp của điều dưỡng: 4,20 $\pm 0,600$. Kết luận: Kết quả của nghiên cứu cho thấy người bệnh có sự hài lòng ở mức độ cao với giao tiếp của điều dưỡng. bệnh

Từ khóa: giao tiếp điều dưỡng, sự hài lòng người

\section{SUMMARY \\ ASSESSMENT OF PATIENT STATISFACTION FROM NURSE COMMUNICATION}

Background: Patient-nurse communication in healthcare was pivotal tool to assess patient satisfaction. Improving nurse communication contribute to patient satisfaction, hence increases quality and effectivenes of healthcare. The aim of this study to assess the association betweeen patient satisfaction and nurse communication. Objective: Assess patient satisfaction from patient-nurse communication at the Neurology Center of Bach Mai Hospital in 2021. Methods: Descriptive crosssectional design. 238 patients were randomly selected. Data based on 36-question self-completed questionnaire were collected. Results: The average age was $52.96 \pm 16.4$ years old, female $(51.3 \%)$, got married $(88 \%)$, have a secondary and high school level in educational stage (45.8 and $34.9 \%$, get health insurance $(89.9 \%)$, the average length of stay in hospital was $5-10$ days (48.3\%). The average score of patient satisfaction and nurse communication was $4.33 \pm 0.516$ and $4.20 \pm 0.600$, respectively. Conclusion: The results show that most patients were high satisfied level with nursing care. Keywords: nurse communication. patient satisfaction. 